Научная статья

УДК 34

https://doi.org/10.36511/2078-5356-2021-3-8-16

Технико-юридическая культура как базовая основа эфффективного функционирования системы властных и невластных начал современного российского права

\author{
Баранова Марина Владимировна', Купцова Ольга Борисовна² \\ 1, 2 Национальный исследовательский Нижегородский государственный университет им. Н. И. Ло- \\ бачевского, Нижний Новгород, Россия \\ 1qazxsw1232007@yandex.ru \\ 2olga.kuptsova@mail.ru
}

Аннотация. Статья посвящена анализу понятия и специфики формирующейся технико-юридической культуры в условиях нового технологического уклада, свойственного постиндустриальному обществу. Правовая культура современного российского общества характеризуется изменением своей сущностной основы, которая базируется на возрождении ряда традиций, формировании новаций в русле активных процессов цифровизации социума, это дает основания полагать, что существует необходимость в выделении и отграничении от смежных правовых явлений самостоятельной правовой категории - технико-юридической культуры. Перспективная актуальность исследования зиждется в первую очередь на вызовах юридической практики, обусловливающих набор четких требований к профессиональной деятельности и подготовке юриста. Признавая справедливость заключения о неразрывной связи правовых и неправовых, властных и невластных регуляторов и инструментов воздействия, следует предположить, что это оказывает существенное влияние на специфику юридической техники, правовой культуры, технико-юридической культуры применительно к различным видам юридической практики. Особую актуальность обретает анализ возможности видового деления технико-юридической культуры, раскрыты основные ее особенности в соответствии с указанными типологическими группами. С опорой на доминантные черты и проявления технико-юридической культуры, подвергнутые анализу в контексте поиска основы эффективного фуннкцинирования системы властных и невластных начал современного российского права, в статье предложено первичное, «рабочее» определение понятия технико-юридической культуры, которая как самостоятельное явление находится в настоящее время в стадии формирования. Ее активное развитие будет способствовать не только совершенствованию правовой культуры в целом, но и развитию различных сфер современного социума.

Ключевые слова: правовая культура, юридическая техника, технико-юридическая культура, властное и невластное в праве

Для цитирования: Баранова М. В., Купцова О. Б. Технико-юридическая культура как базовая основа эфффективного функционирования системы властных и невластных начал современного российского права // Юридическая наука и практика: Вестник Нижегородской академии МВД России. 2021. № 3 (55). С. 8-16. https://doi.org/10.36511/2078-5356-2021-3-8-16.

Original article

\title{
Technical and legal culture as the basic basis for the effective functioning of the system of power and non-power principles of modern Russian law
}

Marina V. Baranova', Olga B. Kuptsova ${ }^{2}$

1, 2Lobachevsky National Research Nizhny Novgorod State University, Nizhny Novgorod, Russian Federation

${ }^{1}$ qazxsw1232007@yandex.ru

²olga.kuptsova@mail.ru

() Баранова М. В., Купцова О. Б., 2021 
Abstract. The article is devoted to the analysis of the concept and specifics of the emerging technical and legal culture in the conditions of a new technological way of life characteristic of post-industrial society. The legal culture of modern Russian society is characterized by a change in its essential basis, which is based on the revival of a number of traditions, the formation of innovations in line with the active processes of digitalization of society, this gives reason to believe that there is a need to distinguish and distinguish from related legal phenomena an independent legal category - technical and legal culture. The prospective relevance of the research is based, first of all, on the challenges of legal practice, which determine a set of clear requirements for the professional activity and training of a lawyer. Recognizing the validity of the conclusion about the inseparable connection of legal and non-legal, power and nonpower regulators and instruments of influence, it should be assumed that this has a significant impact on the specifics of legal technology, legal culture, technical and legal culture in relation to various types of legal practice. The analysis of the possibility of a specific division of technical and legal culture is particularly relevant, its main features are revealed in accordance with these typological groups. Based on the dominant features and manifestations of technical and legal culture, analyzed in the context of the search for the basis for the effective functioning of the system of power and non-power principles of modern Russian law, the article offers a primary, "working" definition of the concept of technical and legal culture, which as an independent phenomenon is currently in the formation stage. Its active development will contribute not only to the improvement of legal culture in general, but also to the development of various spheres of modern society.

Keywords: legal culture, legal technic, technical and legal culture, the imperious and the non-imperious are in the right

For citation: Baranova M. V., Kuptsova O. B. Technical and legal culture as the basic basis for the effective functioning of the system of power and non-power principles of modern Russian law. Legal Science and Practice: Journal of Nizhny Novgorod Academy of the Ministry of Internal Affairs of Russia, 2021, no. 3 (55), pp. 8-16. (In Russ.). http://doi.org/10.36511/2078-5356-2021-3-8-16.

Новый технологический уклад, свойственный постиндустриальному обществу, вносит существенные изменения в понимание места и роли права в современном государстве. Люди, следуя в русле изменений всех ссрер жизни, принимают новые правила упорядочения отношений, сталкиваясь с трудностями, порой пассивно или активно сопротивляясь. Измененная реальность требует нового взгляда на взаимодействие человека и "государственной машины», иной специфики и границ. При этом осознание правовой информации, восприятие юридических инноваций, выстраивание коммуникативного действия, «ориентированного на достижение взаимопонимания и согласия» [1] не теряет своей актуальности, особенно в рамках юридической практики. В сложившихся реалиях особую важность приобретает необходимость осуществления равного, открытого диалога государства и социума, что возможно только в условиях адекватного, продуманного использования технико-юридического инструментария широким спектром лиц с различным уровнем и объемом правовых знаний, умений, навыков. Не случайно именно на этом этапе развития общества проявил себя интерес к крауд-технологиям, позволяющим наметить путь отхода от примата государства в социально значимых вопросах. Перспективное развитие права сегодня представляется в условиях партнерского диалога властного (государственного) и невластного (социального) начал, имеющих общие правокультурные основания.

В современной российской правовой системе типичные для европейской модели государственности идеи партнерства государства и социума претерпели существенные изменения, сообразно специфике национальной культуры, правовой культуры, что естественно и оправданно. Построение действенного механизма такого взаимодействия с использованием достижений технологического прогресса неизбежно и желанно, но в то же время весьма сложно, неоднозначно оценивается обществом, может повлечь биполярные последствия. Следует признать, что любая инновация требует времени, усилий по внедрению, корректировки «проблемных зон». Построение правовой коммуникации в новом формате, непривычными средствами направлено на более обширное внедрение идей делиберативной демократии, воплощающей в реальном бытии равноправное взаимодействие властных и невластных начал права посредством особого технико-юридического инструментария. Уже сегодня проводится активная политика интеграции информационных технологий, опосредующих правовую коммуникацию, в деятельность органов государственной 
власти. Звучат призывы «цифровизировать всю систему государственного управления, повысить прозрачность деятельности госструктур, увеличить скорость обработки обращений граждан, снизить бюрократические барьеры, внедрить новые формы интерактивного взаимодействия с гражданами» [2, с. 24].

В условиях такого органичного погружения в праворегулятивные процессы не только субъектов юридической практики, но и граждан следует признать возрастающую актуальность юридических знаний. На первый план выходит правовая культура социума, поскольку «...правовой механизм представляет собой сложный аппарат, для эффрективной работы которого требуется целенаправленная духовная активность всех членов общества. Каждая личность своим участием в осуществлении права претворяет в социальных отношениях необходимое в требование должного. Этот творческий процесс возможен только благодаря сознательной и волевой деятельности всех членов общества - самодостаточных граждан своего государства» [3, с. 128].

Правовая культура современного российского общества характеризуется изменением своей сущностной основы, которая базируется на возрождении ряда традиций, формировании новаций в русле активных процессов цифровизации социума. В настоящее время есть добротный накопленный опыт доктринальных и научно-практических наработок, содержащих систему требований к созданию различных видов правовых актов, разрабатываемых в русле нижегородской научной школы под руководством В. М. Баранова. В этом отношении базис данного накопленного наследия, его популяризация и практическое воплощение дает основания полагать, что существует необходимость в выделении и отграничении от смежных правовых явлений самостоятельной правовой категории - технико-юридической культуры. Предпосылки к ее выделению постепенно складывались на протяжении определенного количества времени, и в последний период целый ряд исследователей в той или иной мере раскрывали ее аспекты. Так, например, В. М. Баранов ведет речь о законотворческой культуре [4, с. 1], Г. А. Тосунян и Л. В. Санникова исследуют культуру правотворчества [5, с. 28-34], Л. А. Петручак выделяет культуру правотворческой деятельности и правоприменения [6, с. 304], С. Н. Болдырев выделяет культуру юридической техники [7, с. 37], и этот перечень можно продолжить.

Перспективная актуальность исследования технико-юридической культуры зиждется в первую очередь на вызовах юридической практики, обусловливающих набор четких требований к профессиональной деятельности и подготовке юриста. Реалии бытия диктуют необходимость формирования не только широкого спектра специальных знаний, владения приемами и средствами юридической техники, но и реальными умениями и навыками их воплощения в предлагаемых условиях. Только в этом случае можно говорить об эффективности деятельности юриста, эффективности функционирования права в целом. Сегодня юридическая техника гармонично объединяет властное и невластное начала. Отдавая отчет в привычности и первостепенности властной составляющей, подвергаемой регулярному доктринальному анализу, следует признать необходимость обращения к невластным аспектам, обусловливающим иное проявление во вне технико-юридического инструментария. Изначально в российской правовой науке базовым компонентом представлений о юридической технике являлось властное начало техники правотворчества (узкий подход). Позднее укоренился подход, соединивший спектр властной и невластной юридической деятельности и типичный для этого специальный инструментарий (широкий подход). Устоявшийся широкий подход предлагает трактовать юридическую технику как систему «профрессиональных юридических правил и средств, используемых при составлении правовых актов и осуществлении иной юридической деятельности в сорерах правотворчества, правоинтерпретации, властной и невластной реализации права, обеспечивающих совершенство его формы и содержания» [8, с. 32]. В контексте данного подхода субъектный ряд позволяет говорить о технике властной и невластной юридической деятельности. Действительно, властными полномочиями обладают далеко не все субъекты правовой коммуникации, значит, названные виды юридической техники выделить и подвергнуть анализу вполне оправданно, но в реальных отношениях государства и социума все неоднозначно - виды, порой, трудно разделимы, особенно в условиях технологизации.

Использование интернета упростило и ускорило правовую коммуникацию и правовую аккультурацию. Глобализованная, юридизированная реальность для участия в диалоге требует специальных юридических знаний, властных полномочий, владения навыком использования специальных технико-юридических форм. В рамках юридической практики предполагается наличие власти, либо действие от имени власти, 
по властному указанию, в рамках властных требований, форм, компетенции, полномочий. Особо следует отметить, что профессиональная деятельность юриста включает и невластную составляющую - требования к функциональной профессиональной пригодности, требуемые социально-психологические качества. Составляющая, характеризующая личность, позволяет не только выявить акцентуации, черты характера, возможные доминантные модели поведения, готовность к сотрудничеству, но и влияет на набор и сочетание востребуемых в перспективе властных и невластных технико-юридических инструментов, в конечном счете влияет на уровень юридической техники в целом.

В правовой доктрине сложилась достаточно устоявшаяся позиция, в соответствии с которой характеристика уровня сформированности и развития юридической техники позиционируется лишь как показатель правовой культуры общества. Несмотря на это, учитывая уровень развития правовых явлений в современном российском обществе, можно отметить, что данный подход нуждается в корректировке и переосмыслении. Е. Ф. Усманова справедливо акцентирует внимание на том, что юридическая техника рассматривается как средство повышения уровня правовой культуры лишь с точки зрения узкого ее понимания [9, с. 201]. Таким образом, переосмысление понятийного аппарата - это очень актуальная тенденция современности.

В настоящее время понятие культуры в целом является достаточно вариативным и неоднозначно понимаемым, ряд исследователей выделяют достаточно обширный перечень точек зрения, отражающих определение данного понятия. Вместе с тем, представляется эффективной и своевременной наиболее распространенная позиция - в современных научных исследованиях начинает доминировать ценностный (аксиологический) подход, который позволяет относить к культуре не всю человеческую деятельность и ее результаты, а только то, что является благом, определенной ценностью для индивидов и их общностей [6, с. 34]. Кроме того, как справедливо отмечал Г. П. Выжлецов, обосновавший концепцию аксиологии культуры, ценностное учение о культуре, в отличие от множества других теоретических подходов к ней, позволяют увидеть культуру изнутри [10, с. 3]. С точки зрения данной концепции в общем абстрактном понимании правовая культура представляет собой совокупность правовых ценностей, выработанных человечеством, отражающих прогрессивноправовое развитие общества.
Сущностная основа правовой культуры проявляется в процессе влияния на становление и модернизацию значимых социальных институтов. Обладая системным характером, правовая культура вбирает и упорядочивает юридические ценности, фриксирует уровень развития юридической техники, инструментальной ценности права в рамках конкретного отрезка времени. В России правовая культура обладает ярко выраженной особенностью - она исторически сложилась на основе базового ценностного ориентира «правды»/«справедливости»/«совести», причем отголоски ключевых компонентов этого подхода в той или иной мере проявляют себя в современной правовой культуре страны и национальной правовой системе в целом. Названные компоненты изначально буквально служили для оценки поведения, выбора модели поведения, фрормы осуществления функций права. Понимание права, требования государственно-властных велений и представления о «правде»/«справедливости» / «совести» на протяжении длительного времени вступали в противоречия, вызывали конфликтные ситуации. Безусловно, право «всегда ассоциировалось с порядком, законами, устанавливающими порядок, и в этом отношении оно универсально. Право четко вписывается в структуры бытия, если они устойчивы и целостны, но дестабилизация и разрушение порядка, произвол, хаос ослабляют, а затем прекращают действие права» [11, с. 6]. Концепция «правда»/«справедливость»/«совесть» как базовая мера в правовых (властных) и иных социальных (невластных) вопросах по сей день органично существует в национальной правовой системе. Она устойчива к дестабилизации, способна модернизироваться в соответствии с реалиями. Специфика понимания правовой культуры проявляется в современных правовых установлениях, обусловливает взаимодействие государства и социума, соотношение властного и невластного начал в юридической технике, возведение того или иного явления, предмета в ранг ценности.

У проблемы определения понимания и содержательных характеристик обобщенной категории ценностей существует вариативность решения, основанная на нескольких точках зрения, раскрывающих эту категорию. Причем они располагаются между крайностями субъективно-релятивистских и объективно-абсолютистских концепций [10, с. 51]. Вместе с тем, правовые ценности выступают в качестве критериев оценки реально существующих правовых явлений и процессов [12, с. 33]. И если 
технико-юридическая культура, существующая в социуме, представляет собой элемент правовой культуры общества в целом, то можно предположить, что ее ценностные составляющие являются в определенной степени факторами развития правокультурных аксиологических конструкций в целом.

Правовые ценности достаточно многообразны, причем ценности технико-юридической культуры являются производными от них. Так, например, справедливость и законность как правовые ценности находят выражение в аксиологических конструкциях справедливости нормативных правовых актов или законности правоприменительных актов. При этом существенную роль в их формировании играет юридико-технический инструментарий. Технико-юридическая культура проявляется в формировании, передаче, сохранении правовых ценностей, служащих ориентиром юридически значимого поведения по созданию и изменению нормативных правовых, интерпретационных, правоприменительных и правосистематизирующих актов.

Спектр ценностей, лежащих в основе системы оценки правовых явлений и процессов, распространяет свое влияние и на неправовые регуляторы (невластное), поскольку они в той или иной мере обусловлены правом (властное), с ним взаимосвязаны, им опосредованы, его опосредуют. В настоящее время социальные неправовые регуляторы привлекают внимание правоведов, поскольку явно видна их важность для широкого спектра отношений. Так, профессор Ю. А. Тихомиров, обращаясь, по сути, к вопросу допустимости перспективного слияния правовых и неправовых регуляторов, предложил свое видение социальной концепции права. В исследовании, посвященном прогнозам и рискам в праве, он отметил, что «в российском законодательстве социальные регуляторы нашли отражение в содержании экономических и иных отраслей права» [13, с. 97]. Акцент на правовых и неправовых социальных нормах, понимание непосредственно их ценности, анализ сопряженных правовых ценностей позволят более эффективно осуществлять правовую регламентацию. Р. Пэнто и М. Гравитц, анализируя методы социальных наук, отмечали, что «в виде правовых норм могут выступать различные социальные нормы» [14, с. 54]. «Всякая социальная группа характеризуется соответствующим нормативным порядком. Нормативный порядок политического общества исключительно и безраздельно является правовым. Политическое общество целиком основано на праве. Напротив, нормативный порядок других социальных групп предполагает наличие неправовых норм. Так, нормативный порядок конгрегации (при принципе отделения церкви от государства) включает в себя правила, не обладающие правовыми свойствами. Нормативный режим семейной группы также является частью правовым, частью неправовым» [14, с. 59]. Признавая справедливость заключения о неразрывной связи правовых и неправовых, властных и невластных регуляторов и инструментов воздействия, следует предположить, что это оказывает существенное влияние на специфику юридической техники, правовой культуры, технико-юридической культуры применительно к различным видам юридической практики. В этой связи особую актуальность обретает анализ возможности видового деления технико-юридической культуры в соответствии с разновидностями юридической техники на правотворческую, правоинтерпретационную, правоприменительную, правосистематизирующую и др. Обращаясь к анализу характерных особенностей формирования исследуемого правового феномена, отметим важнейшие из них в соответствии с указанными типологическими группами.

Специфика правотворческой юридической техники получила достаточно детальное освещение в доктринальных изысканиях. В настоящее время существует потребность в специалистах-профессионалах, которые обладали бы навыками подготовки качественных нормативных правовых актов и иных источников права, основываясь на зрелом технико-юридическом сознании, осознании необходимости подготовки качественных нормативных документов. Безусловно, не стоит сбрасывать со счета активизацию включенности граждан в процессы делиберации. Российское государство выражает свою властную заинтересованность в этом. Так, в 2011 году был сделан серьезный шаг в признании ценности участия широкого круга граждан в процессе правообразования - вступили в силу: Указ Президента РФ от 9 февраля 2011 года № 167 «Об общественном обсуждении проектов федеральных конституционных законов и федеральных законов» и Указ Президента РФ от 4 марта 2013 года № 183 «О рассмотрении общественных инициатив, направленных гражданами Российской Федерации с использованием интернет-ресурса "Российская общественная инициатива"».

Признавая безусловную значимость делиберативных процессов, следует отметить 
сложность этой задачи. Недостаточность, а порой и полное отсутствие правовых знаний, умений обращения с правовой материей, технико-юридическим инструментарием программируемо вызывает труднопреодолимые или неустранимые проблемы в оценивании действующих и желаемых правовых регламентов. Доступный спектр технико-юридических средств неоправданно сужается, примитивизируются подходы, формы, обедняются идеи. Профессиональное же владение юридической техникой предоставляет богатство возможностей и инструментов, уместный выбор которых основан на системных правовых знаниях, специфическом критическом мышлении, опыте, навыках и умениях. В правотворчестве это особенно важно, поэтому, следует выразить согласие с позицией профессора В.М.Баранова о необходимости профессионализации процесса нормотворчества. На данном этапе развития и востребования практикой знаний о юридической технике актуальным представляется вопрос организации подготовки «норморайтеров» - специалистов, которые не принимают нормативные правовые акты, а именно пишут их, разрабатывают структуру и архитектонику документа [15, с. 21].

Профессиональная деятельность юриста оказывает существенное влияние на правовую культуру общества, ее уровень. При этом следует отметить, что технико-юридическая культура в этом плане в первую очередь характеризуется высоким уровнем сформированности навыков создания качественных законодательных дефиниций.

Несмотря на то что в настоящее время в современной российской правовой системе сложился в той или иной степени достаточно качественный и, самое главное, работающий массив нормативных предписаний, целый перечень легальных дефиниций нуждается в совершенствовании по причине неполного соответствия правилам юридической техники. Качественные упущения в формулировании норм права влекут снижение эффрективности правоприменения, затруднения в системном толковании норм права и иные негативные последствия, в том числе возникновение ситуации правовой неопределенности, возможно, даже пробельности в правовом регулировании. Учет требований юридической техники является конструктивной тенденцией современной правовой действительности.

Среди характерных особенностей техникоюридической культуры также следует отметить постепенное формирование позитивного отношения к использованию иноязычной лексики в текстуальном выражении нормативных предписаний различных источников права. Это является отражением не только развивающейся правовой культуры общества, которая характеризуется возрождением традиций латинской юридической терминологии в языке права и языке правовой доктрины, но и является следствием развития лингвистической культуры, которая в условиях цифровизации общественных отношений отличается активным внедрением в словарный запас иноязычной лексики, например, таких терминов, как «майнинг», «криптовалюта» и т. д. Есть основания полагать, что разумно и своевременно используемая иностранная лексика способствует развитию права, обогащению его новыми конструкциями, которые имеют более эфффективный регулятивный потенциал.

Специфической чертой сложившейся российской правоинтерпретационной технико-юридической культуры является недостаточная готовность субъектов права к конструктивной, эффективной и своевременной интерпретации нормативных установлений и, кроме того, к эффективному мониторингу в этой сфере.

Правоприменительная технико-юридическая культура в современной российской правовой системе отличается все возрастающей степенью шаблонизации формулирования индивидуальных предписаний. Стоит также отметить некоторую степень волюнтаризма правоприменителя при их создании. Нет оснований не согласиться с мнением профессора В. П. Малахова, который справедливо обращает внимание на то, что своеобразие российской духовности заключено в базовом сочетании религиозности и моральности. Причем смысл российской моральности в восприятии социальной реальности заключается в первую очередь в пассивно-критическом, иронично-скептическом отношении [16, с. 352-353]. В этом и находят проявление доминанты духовности и системообразующие идеи российской правовой культуры в целом.

Следующая разновидность - правосистематизирующая технико-юридическая культура отличается недостаточным уровнем своего развития. В связи с этим в сфрере профессиональных правовых ценностей необходимо формирование установки на правовую активность в данной сорере деятельности, законодательно следует предусмотреть правомочия реагирования для инициирования различных правосистематизирующих процедур. 
Кроме того, следует отметить еще один аспект формирования современной технико-юридической культуры - развитие вариативности технико-юридического сознания. В настоящее время идут активные процессы трансформации сложившихся представлений о фоомулировании и специфике нормативных предписаний и их взаимосвязи с иными феноменами. В нашу эпоху второго модерна меняется специфика анализа и обработки правовой информации. В связи с этим необходимо на перспективу прорабатывать варианты оперирования нормами права, которые объединяются в определенные комплексы системного характера, и использовать в своей работе иное структурирование нормативного материала. Бесспорно, что в настоящее время это пока не требование правовой действительности, но осмысление и формирование предпосылок развития данного направления деятельности необходимо осуществлять уже сейчас, чтобы правовая система и специалисты были готовы к изменениям социальной действительности в целом и юридической действительности в частности. Профрессор И. В. Понкин отмечает важный аспект правового развития - концепт машиночитаемого права и машиноисполняемого права, который является одним из основных направлений цифрровых трансформаций в праве, что потребует изменения подходов к юридической технике и самому процессу правового регулирования [17, с. 61].

Есть основания полагать, что в русле указанных правовых трансформаций конструктивными, своевременными и востребованными юридической практикой будут исследования топики в праве. Топы юридического языка как структурно-смысловые модели языкового характера обладают существенным потенциалом совершенствования юридико-технических составляющих правовой материи.

Нормативные установления современной системы источников права постепенно подвергаются изменениям как содержательного, так и формального характера в связи с продолжающимися процессами глобализации и цифровизации права. И в данном русле трансформационных процессов топическую юриспруденцию можно позиционировать как одно из важнейших направлений основ не только культуры юридического языка, но и технико-юридической культуры. К топам юридического языка следует относить структурные элементы текста правового акта, которые имеют свою содержательную наполненность и взаимодействуют между собой, предопределяя дополнительную внутреннюю структуризацию права, а также и интерпретационных и правоприменительных положений.

Здесь важно отметить, что на понимание текста, понятийного аппарата существенное влияние оказывает специфика личности субъекта восприятия. Различия в образовательном уровне, специфика знаний, социальный статус, жизненный опыт, степень владения языком, ментальные особенности играют значимую роль. В правоведении устоялось справедливое убеждение в том, что юридический язык формирует специфическое юридическое мышление. Универсальность и системность ключевых компонентов юридического языка позволяют четко и корректно выразить, уяснить, разъяснить, реализовать (властно и невластно) нормативное веление. Глобализованный мир вовлекает национальные правовые системы в мировые процессы, активную правовую аккультурацию, взаимодействие в социальных и политических ссрерах, что актуализирует обращение к исследованию современных процессов транстерминологизации, универсализации, стандартизации элементов языка права, служащих цели эфрфективного фуункционирования системы властных и невластных начал современного российского права.

Взаимозависимость этих начал в национальном праве России, в юридической технике, как ранее отмечалось, исторически обусловлено сформированным в правовой культуре балансом государственных властных велений и ценностного ориентира «правды»/«справедливости»/«совести». Гармоничное, взаимообусловленное сосуществование властных и невластных начал обогащает правовую культуру и юридическую практику, предоставляя инновационные возможности использования технико-юридического инструментария, создает ресурс для результативной правовой коммуникации государства и социума. Технико-юридическая культура в рамках юридической практики основывается на восприятии субъекта с позиций его индивидуальной культуры, его знаний и умения владеть технико-юридическим инструментарием.

Опираясь на доминантные черты и проявления технико-юридической культуры, подвергнутые анализу в контексте поиска основы эфффективного функционирования системы властных и невластных начал современного российского права, можно предложить первичное, «рабочее» определение понятия технико-юридической культуры:

Технико-юридическая культура - часть правовой культуры, представляющая собой 
систему технико-юридических (властных) и этико-деонтологических (невластных) ценностей, уровня развития юридической техники, осознанного уважительного отношения к техникоюридическому инструментарию, служащую базовой основой эффективности воплощения в юридической практике профессиональных юридических правил, приемов, средств, необходимых для качественного функционирования сфер правотворчества, правоинтерпретации, властной и невластной реализации права, обеспечения совершенства формы и содержания права.

Технико-юридическая культура как самостоятельное явление находится в настоящее время в стадии формирования, ее активное развитие будет способствовать не только совершенствованию правовой культуры в целом, но и развитию различных сфер современного социума. Экстраполируя авторитетное заключение профессора Г. В. Мальцева о том, что «...уровень культуры отражает меру воспроизводимости факторов порядка в противовес хаотическому состоянию общественной жизни» [11, с. 6], можно с высокой долей уверенности говорить о неоспоримой ценности технико-юридической культуры как перспективного феномена, отражающего меру должного порядка в юридической технике, в противовес сущему - состоянию, проблемам, отклонениям от жестких и оправданных технико-юридических требований во всех сфрерах юридической практики (властной и невластной).

\section{Список источников}

1. Хабермас Ю. Моральное сознание и коммуникативное действие. СПб., 2000. 382 с.

2. Баканова Е. А. Технонаука в информационном обществе: социально-философский анализ: автореф. дис. ... канд. филос. наук. Томск, 2020.

3. Фролова Е. А. Методология и фрилософия права: от Декарта до русских неокантианцев: монография. М., 2017. 346 с.

4. Культура и юридическая техника. Вступительное слово профессора Владимира Михайловича Баранова // Юридическая техника. 2016. № 10. С. 10-22.

5. Тосунян Г. А., Санникова Л. В. Культура правотворчества в современной России // Государство и право. 2018. № 3. С. 28-34.

6. Петручак Л. А. Правовая культура современного российского общества: теоретико-правовое исследование: дис. ... канд. юрид. наук. М., 2012. 453 с.

7. Болдырев С. Н. Правовая культура общества и культура юридической техники // Философия права. 2011. № 1. С. $36-40$.
8. Юридическая техника: в 2 т. Т. 1: учебник для вузов / под ред. В. М. Баранова. М., 2016. 251 с.

9. Усманова Е. Ф. Юридическая техника и правовая культура: проблемы взаимодействия // Современные проблемы общественных, экономических и правовых наук: теория и практика: материалы Bceроссийской научной конференции с международным участием «XVII Маркинские научные чтения». Саранск, 2017. С. 200-201.

10. Выжлецов Г. П. Аксиология культуры. СПб., 1996. 148 c.

11. Мальцев Г. В. Культурные традиции права: монография. М., 2013. 607 с.

12. Петручак Л. А. Правовая культура: обоснование аксиологического подхода // Актуальные проблемы российского права. 2009. № 3. С. 30-39.

13. Тихомиров Ю. А. Право: прогнозы и риски: монография. М.: Институт законодательства и сравнительного правоведения при Правительстве Российской Федерации, 2015. 240 с.

14. Пэнто Р., Гравитц М. Методы социальных наук. М., 1972.607 c.

15. Баранов В. М. Норморайтер как профессия // Вестник Саратовской государственной юридической академии. 2017. № 6. С. 16-29.

16. Малахов В. П. Правосознание: природа, содержание, доктрина. М., 2001. 385 с.

17. Понкин И. В. Концепт машиночитаемого и машиноисполняемого права: актуальность, назначение, место в PerTexe, содержание, онтология и перспективы // Interrnational Journal of Open Information Tecnologies. 2020. № 9. C. 59-69.

\section{References}

1. Habermas Yu. Moral consciousness and communicative action. St. Petersburg, 2000. 382 p. (In Russ.)

2. Bakanova E. A. Technoscience in the information society: socio-philosophical analysis. Author's abstract... candidate of philosophical sciences. Tomsk, 2020. (In Russ.)

3. Frolova E. A. Methodology and philosophy of law: from Descartes to the Russian neo-Kantians: monograph. Moscow, 2017. 346 p. (In Russ.)

4. Culture and legal technology. Introductory speech by Professor Vladimir Mikhailovich Baranov. Legal technique, 2016, no. 10, pp. 10-22. (In Russ.)

5. Tosunyan G. A., Sannikova L. V. Culture of lawmaking in modern Russia. State and law, 2018, no. 3, pp. 28-34. (In Russ.)

6. Petruchak L. A. Legal culture of modern Russian society: theoretical and legal research. Dissertation... candidate of legal sciences. Moscow, 2012. 453 p. (In Russ.)

7. Boldyrev S. N. The legal culture of society and the culture of legal technology. Philosophy of law, 2011, no. 1, pp. 36-40. (In Russ.) 
8. Legal equipment: in 2 vol. Vol. 1: Textbook for universities / ed. by V. M. Baranov. Moscow, 2016. 251 p. (In Russ.)

9. Usmanova E. F. Legal technique and legal culture: problems of interaction. Modern problems of social, economic and legal sciences: theory and practice: materials of the All-Russian Scientific Conference with international participation "XVII Markinsky Scientific readings". Saransk, 2017. Pp. 200-201. (In Russ.)

10. Vyzhletsov G. P. Axiology of culture. St. Petersburg, 1996. 148 p. (In Russ.)

11. Maltsev G. V. Cultural traditions of law: monograph. Moscow, 2013. 607 p.

12. Petruchak L. A. Legal culture: justification of the axiological approach. Actual problems of Russian law, 2009, no. 3, pp. 30-39. (In Russ.)
13. Tikhomirov Yu. A. Law: forecasts and risks: monograph. Moscow: Institute of Legislation and Comparative Law under the Government of the Russian Federation Publ., 2015. 240 p. (In Russ.)

14. Panto R., Gravitz M. Methods of social sciences. Moscow, 1972. 607 p. (In Russ.)

15. Baranov V. M. Standard writer as a profession. Bulletin of the Saratov State Law Academy, 2017, no. 6, pp. 16-29. (In Russ.)

16. Malakhov V. P. Legal consciousness: nature, content, doctrine. Moscow, 2001. 385 p. (In Russ.)

17. Ponkin I. V. The concept of machine-readable and machine-executable law: relevance, purpose, place in PerText, content, ontology and prospects. Interrnational Journal of Open Information Tecnologies, 2020, no. 9, pp. 59-69. (In Russ.)

\section{Информация об авторах}

М. В. Баранова - доктор юридических наук, кандидат культурологии, профессор, почетный работник высшего профессионального образования Российской Федерации;

О. Б. Купцова - кандидат юридических наук, доцент.

\section{Information about the authors}

M. V. Baranova - Doctor of Sciences (Law), Candidate of Science (Cultural Study), Professor, Honorary Worker of Higher Professional Education of the Russian Federation;

O. B. Kuptsova - Candidate of Science (Law), Assistant Professor.

Статья поступила в редакцию 12.05.2021; одобрена после рецензирования 27.08.2021; принята к публикации 31.08.2021.

The article was submitted 12.05.2021; approved after reviewing 27.07.2021; accepted for publication 31.08.2021. 